\title{
How consumer digital signals are reshaping the customer journey
}

\author{
David A. Schweidel ${ }^{1} \cdot$ Yakov Bart $^{2} \cdot$ J. Jeffrey Inman ${ }^{3} \cdot$ Andrew T. Stephen $^{4} \cdot$ Barak Libai $^{5} \cdot$ Michelle Andrews $^{1}$. \\ Ana Babić Rosario ${ }^{6}$ (1) $\cdot$ Inyoung Chae ${ }^{1} \cdot$ Zoey Chen $^{7} \cdot$ Daniella Kupor $^{8} \cdot$ Chiara Longoni $^{8} \cdot$ Felipe Thomaz $^{4}$
}

Received: 3 January 2021 / Accepted: 12 January 2022 / Published online: 19 February 2022

(C) Academy of Marketing Science 2022

\begin{abstract}
Marketers are adopting increasingly sophisticated ways to engage with customers throughout their journeys. We extend prior perspectives on the customer journey by introducing the role of digital signals that consumers emit throughout their activities. We argue that the ability to detect and act on consumer digital signals is a source of competitive advantage for firms. Technology enables firms to collect, interpret, and act on these signals to better manage the customer journey. While some consumers' desire for privacy can restrict the opportunities technology provides marketers, other consumers' desire for personalization can encourage the use of technology to inform marketing efforts. We posit that this difference in consumers' willingness to emit observable signals may hinge on the strength of their relationship with the firm. We next discuss factors that may shift consumer preferences and consequently affect the technology-enabled opportunities available to firms. We conclude with a research agenda that focuses on consumers, firms, and regulators.
\end{abstract}

Keywords Technology-enabled customer journey $\cdot$ Consumer digital signals $\cdot$ Consumer privacy $\cdot$ Personalization $\cdot$ Firm capabilities $\cdot$ Conceptual framework $\cdot$ Research agenda

Dhruv Grewal served as Guest Editor for this article.

David A. Schweidel

dschweidel@emory.edu

Yakov Bart

y.bart@northeastern.edu

J. Jeffrey Inman

jinman@katz.pitt.edu

Andrew T. Stephen

andrew.stephen@sbs.ox.ac.uk

Barak Libai

libai@idc.ac.il

Michelle Andrews

m.andrews@emory.edu

Ana Babić Rosario

ana.babic-rosario@du.edu

Inyoung Chae

inyoung.chae@emory.edu
Zoey Chen

zchen@bus.miami.edu

Daniella Kupor

dkupor@bu.edu

Chiara Longoni

clongoni@bu.edu

Felipe Thomaz

felipe.thomaz@sbs.ox.ac.uk

Emory University, Atlanta, GA, USA

Northeastern University, Boston, MA, USA

3 University of Pittsburgh, Pittsburgh, PA, USA

4 University of Oxford, Oxford, UK

5 Interdisciplinary Center, Herzliya, Israel

6 University of Denver, Denver, CO, USA

7 University of Miami, Coral Gables, FL, USA

8 Boston University, Boston, MA, USA 


\section{Introduction}

The development and deployment of new technologies ${ }^{1}$ are radically changing how consumers search for information, evaluate products and services, make purchase decisions, and share their experiences with others. Many of these changes are driven by technological investments in novel marketing opportunities. For example, $\$ 50$ billion is projected to be spent on marketing technologies globally by 2023 (Forrester, 2019). While firms invest in technology for various marketing purposes, the potential returns on their investments hinge on understanding how technologies can be used to better manage the customer journey. Ultimately, obtaining a dynamic view of the customer across known and unknown interactions may help firms increase sales, improve customer satisfaction, and grow customer lifetime value (Oracle, 2018).

In this article, we introduce the notion of consumer digital signals - tangible and intangible interactions between consumers and the firm that may be observable or unobservable to firms - as indicators of consumer interests, preferences, and activities during their journey. In addition to their visibility to firms, signals may be overtly or covertly collected (e.g., Martin \& Murphy, 2017; Xu et al., 2011). That is, consumers may vary in their awareness and knowledge with which they generate and emit signals. We discuss consumers' emission of signals throughout their journeys, relating them to the tradeoff between consumers' desire for privacy and expected personalization from the firm.

Growth in the popularity of consumer-facing technologies has pushed the notion of consumer signals into the spotlight. From digital assistants and smart thermostats to wearables and connected devices, consumers continually interact with devices capable of collecting and transmitting information pertaining to their actions and intentions (Puntoni et al., 2021). There were an estimated 22 billion connected devices in 2018, and this number is expected to double by 2030 (Statista, 2022).

Recently, major technology companies have been taking steps toward restricting how digital signals can be collected by firms and linked to consumers. For example, Apple updated the iOS operating system, now prompting users to choose whether an app may collect data that can be linked to their device (Ingram, 2021). Two months after the update, more than $80 \%$ of app users in the U.S. chose to restrict tracking when prompted (Laziuk, 2021). The impact of Apple's mobile operating system update giving consumers greater control over who has access to their data is reverberating through the digital marketing ecosystem. According to one

\footnotetext{
"We use the term "technology" consistent with the Merriam-Webster definition of technology as "a manner of accomplishing a task especially using technical processes, methods, or knowledge."
}

report, the enhanced privacy controls available to iOS device owners cost social media platforms nearly $\$ 10$ billion in lost revenue during the second half of 2021 (Stanley, 2021). Google has also taken steps that could curtail the signals that can be linked to consumers, seeking to replace the third-party tracking cookie with clusters of similar consumers (Temkin, 2021) and planning to implement similar policies as Apple for their mobile operating system (Nguyen, 2021). As these changes demonstrate, consumer signals are being increasingly considered by technology providers. At the same time, important questions arise as to the impact of such technologies for marketing.

We posit that the firm's ability to leverage consumer digital signals depends on its capability to gather, analyze, and act on such data. The technology-enabled customer journey, rooted in the idea of consumer digital signals, manifests from the interplay of the firm's capabilities and consumers' knowledge and preferences. We depict this process against the backdrop of the consumer-firm relationship in Fig. 1.

We next discuss how firm technology enables the (1) collection of, (2) interpretation of, and (3) action on these consumer digital signals to manage the journey. A growing body of literature focuses on the impact of specific emerging technologies on consumer behavior and firm actions across various marketing contexts (e.g., Shankar et al. (2021) discuss how technological changes are transforming retailing). Prior research has examined the consequences of adopting mobile devices (e.g., Grewal \& Stephen, 2019; Melumad et al., 2019; Ransbotham et al., 2019; Ward et al., 2017), facial expression detection (e.g., Bharadwaj et al., 2021; De Keyser et al., 2021; Suk \& Prabhakaran, 2014; Tong et al., 2020), artificial intelligence (e.g., Davenport et al., 2020; Dawar, 2018; Leung et al., 2018; Libai et al., 2020; Longoni et al., 2019), and connected devices (e.g., Novak \& Hoffman, 2019). We draw on current examples of customer-firm interactions driven by these technologies to illustrate the building blocks of our approach.

Our proposed framework is not bound to any particular technology but can be applied to understand the impact of any current and future technology from a consumer-firm perspective. As illustrated in Fig. 1, these roles are iterative and shaped by the evolution of the relationship between the consumer and the firm as well as the regulations governing these relationships. The signals consumers generate along their purchase path may be collected by firms with the necessary technological (and/or financial) abilities. How firms interpret and act on these signals may affect how consumers react, and in turn, the signals they subsequently emit. As consumers develop deeper relationships with firms marked by greater satisfaction with their offerings and more trust in the interactions, they may expect more personalization, which may lead them to relax their desire for privacy and to be willing to emit more signals from their activities. 


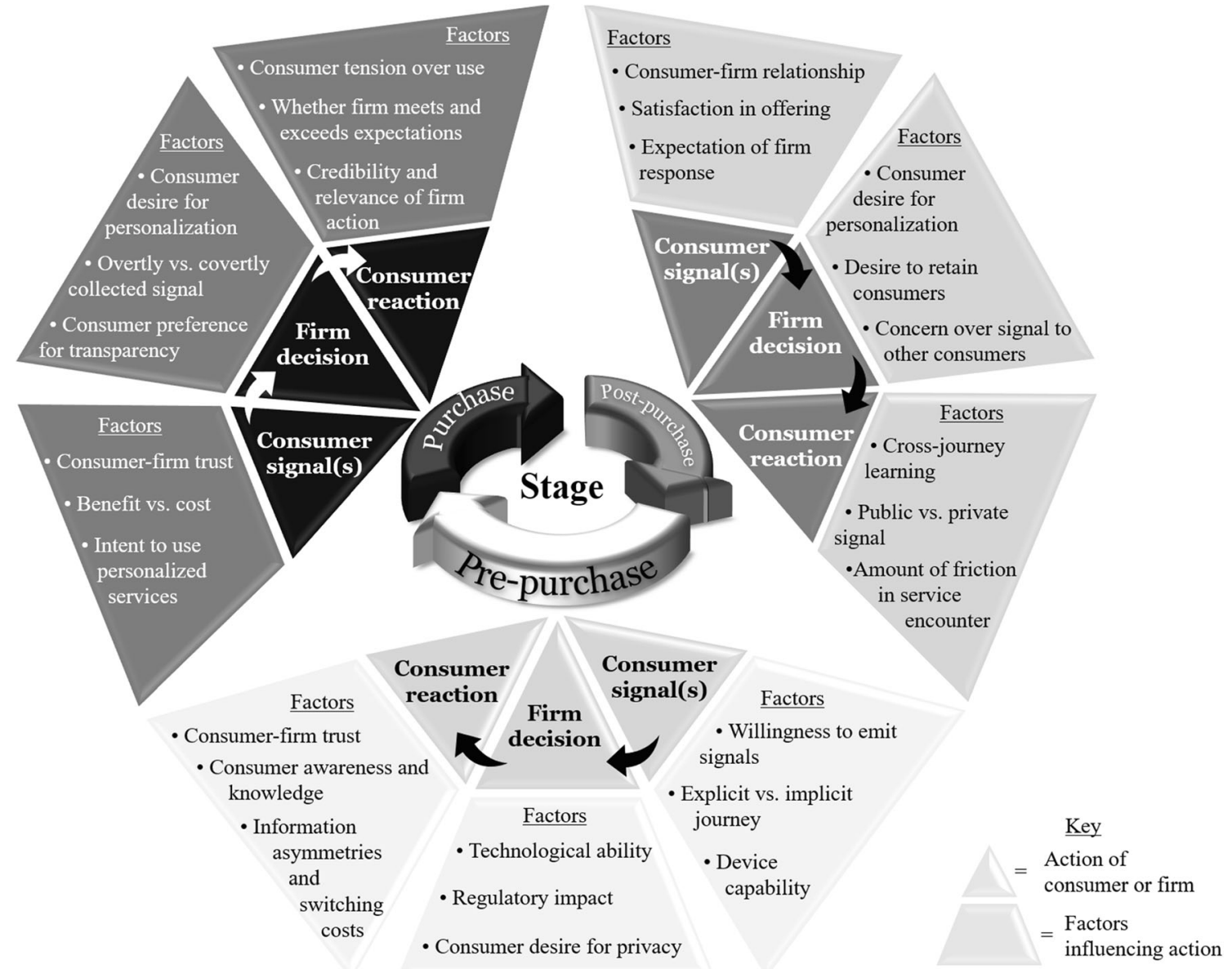

Fig. 1 The role of consumer signals throughout the technology-enabled customer journey

Lastly, we discuss factors that may shift consumers' preferences for privacy vs. personalization and factors that may affect firms' abilities to act on the signals consumers produce. In addition to the roles of the consumer and firm, we include the potential role that policymakers play in regulating the collection and use of consumer signals. We conclude by outlining an agenda of research for future work.

\section{The role of consumer digital signals throughout the customer journey}

Prior research on customer journeys has largely focused on distinguishing the stages (pre-purchase, purchase, post-purchase) and documenting how customers move along them (e.g., Howard \& Sheth, 1969; Lemon \& Verhoef, 2016; Verhoef et al., 2009). Prior work has also discussed how customer decision rules may differ across stages (e.g., two-stage consideration-then-choice models; Bettman \& Park, 1980; Hamilton et al., 2020; Schamp et al., 2019). Most conceptualizations of customer journey touchpoints involve isolated events and individual contacts between customers and firms at distinct points in time, when customers directly indicate their interest in an offering (e.g., De Keyser et al., 2021; Hildebrand \& Schlager, 2019).

The advent of new technologies requires us to augment the traditional conceptualization of the customer journey. Marketing scholars have responded to this change by incorporating digital and new media channels into the consideration and purchase stages (e.g., Elberse, 2010; Kannan \& Li, 2017; Shankar et al., 2011) and modeling cross-channel effects in which customers alternate between intentional and unsolicited exposure to both offline and online marketing (e.g., Anderl et al., 2016; Srinivasan et al., 2016). While some of these frameworks relax the linear assumption of the customer journey and allow for iterative and dynamic interactions between online and offline channels, the customer journey continues to be structured around customer activities in the pre-purchase, purchase, and post-purchase stages (Grewal \& Roggeveen, 2020; Hamilton et al., 2020; Lemon \& Verhoef, 2016).

Our goal in this research is to introduce the critical role that consumer digital signals play in a technology-enabled customer journey. By focusing on the signals produced by consumer activities as they embark on increasingly interconnected customer journeys with less defined beginnings and ends, we 
contribute to the customer journey literature in three important ways. First, we recognize that digital technology such as artificial intelligence agents like Amazon Alexa and Google Home as well as autonomous systems (e.g., De Bellis \& Johar, 2020) enable firms to collect the growing volume of consumers' signals throughout their journeys. These signals could then be used for personalized and targeted marketing efforts. While prior conceptualizations of the customer journey focus on specific actions undertaken by consumers as they interact with the firm (e.g., identifying a consideration set, purchasing, spreading word of mouth), we focus on the multitude of signals that consumers emit from a broad range of everyday behaviors, which may be incredibly informative of their future behavior.

Second, we incorporate into the customer journey the evolving roles of consumer awareness, knowledge, and preferences with regard to privacy and personalization. Not only do these evolving roles affect consumers' signal emission, they also impact how firms choose to engage with consumers throughout the journey by collecting and acting on their signals. The digital exhaust left in the wake of everyday routines produces signals throughout the pre-purchase, purchase, and post-purchase stages of an explicit customer journey. For example, the retail locations consumers visit are captured in mobile device location data. The websites they visit are tracked by ad networks. More generally, consumer signals allow customer journeys that occur in distinct product categories to be interrelated and post-purchase actions to subsequently affect pre-purchase or purchase decisions in the same or different product categories.

Third, while the origin of consumer digital signals may relate to a specific journey, we broaden the conceptualization of the customer journey by recognizing that signals can occur when a consumer is not on an explicit journey. Rather, consumer digital signals are a byproduct of consumers' actions. With new technologies rapidly extending the range of behaviors that firms can observe, such signals have the potential to serve as indicators that portend the beginning of a traditional customer journey. We present the novelties of the technologyenabled journey framework in Table 1.

The technology-enabled customer journey can be perceived as a network of blended journeys that are linked through the consumer digital signals associated with distinct journeys. For example, a consumer may post on social media after purchasing a particular brand, perhaps tagging social ties or indicating her purchase location. Beyond serving as a postpurchase signal that is relevant to the purchased brand, such a post may serve as a series of pre-purchase signals for other brands in the same or different categories based on the similarities identified between consumers who have been observed to interact with multiple brands (e.g., Yang et al., 2021). As such, a single consumer signal has the potential to trigger a chain reaction, serving as a beacon of a consumer's current interests to brands that have necessary technological capabilities to collect and interpret such signals. While the brand with which the consumer recently transacted may view this as an opportunity to deepen the relationship, other brands may act on these signals and engage a prospective customer. Still others may observe the signal and decide not to act if they estimate the expected costs to attract such a consumer to exceed the expected benefit.

A firm's ability to actively manage the customer journey depends on its capability to collect, interpret, and ultimately act on these signals. As Google's chief economist Hal Varian asserts, every customer action can be "considered a signal to be analyzed and fed back into the system" (Zuboff, 2019, p. 69). In marketing contexts, modern technologies allow marketers to capture consumer actions across a range of instances and convert them into signals that can be interpreted and potentially acted on.

\section{Consumer signal visibility and aggregation level}

The emission of digital signals from consumers depends on consumers' adoption of technologies (Inman \& Nikolova, 2017; Wu \& Lederer, 2009). Whereas some consumers may adopt technologies for utilitarian reasons (e.g., ease of task completion), others may do so for hedonic and social reasons (e.g., enjoyment, identity signaling; Blut \& Wang, 2020). For example, many consumers use navigation apps (e.g., Google Maps, Waze) because of the app benefits (e.g., real-time information on routes). As consumers use these technologies, they emit geolocation signals that firms can use to target audiences (e.g., Fong et al., 2015) and that governments can use to monitor the spread of disease (Copeland, 2020). This example showcases a simple yet powerful notion: creating technologies to facilitate tasks can promote the collection of valuable consumer signals by accelerating technology adoption.

In examining the customer journey through the lens of the signals emitted by consumers and the ability of firms to act on those signals, signal visibility plays a critical role. The visibility of the signal depends on the extent to which a consumer is comfortable with the signal being observed by others (other consumers and/or other firms). Signal visibility also depends on the capabilities of the firm. Table 2 illustrates signals that may be generated at each stage of the customer journey and how they may vary in visibility.

We propose three categories of consumer digital signals based on their visibility: anonymous, privately observable, and publicly observable. Anonymous signals refer to those that are emitted and can be detected but cannot be tied to a specific individual. Anonymous signals can stem from technology that simply counts consumers (e.g., when they enter a physical location) rather than identifying a specific individual, 
Table 1 Factors in technology-enabled customer journeys

\begin{tabular}{|c|c|c|c|}
\hline $\begin{array}{l}\text { Technology- } \\
\text { enabled } \\
\text { Customer } \\
\text { Journey Factors }\end{array}$ & Description & Illustrative Research & Examples from Current Marketing Practice \\
\hline
\end{tabular}

\begin{tabular}{cc}
\hline Stakeholders & Customers, firms, competitors, regulators, \\
& other stakeholders, technology \\
providers, technology (e.g., AI, IoT, & sensor-equipped devices). \\
Because technological advances can detect \\
consumer digital signals and convert \\
them into measurable information, \\
technology is embedded throughout \\
customer journeys; devices are \\
interconnected and have agency; mobile \\
devices offer location-based, \\
facial-coding equipped, time-sensitive \\
opportunities for customer-firm \\
touchpoints. \\
Tangible and intangible customer-firm \\
interactions that may be observable or \\
unobservable to firms and that serve as \\
indicators of consumer interests, \\
preferences, and activities during their \\
journey. Signals vary in visibility \\
(anonymous, privately observable, or \\
pubigital \\
pignals \\
(individual, segment, aggregate), and \\
firms' collection efforts (overt, covert). \\
Signals are byproducts of consumer \\
actions and can occur when a consumer \\
is not on an explicit journey.
\end{tabular}

Consumer

Awareness,

Knowledge,

and Privacy

Preferences

Firm
Capabilities
Consumers may be unaware of signals emitted from their devices (e.g., location pings); consumer choice is limited by technology (e.g., virtual assistants such as Amazon Alexa); consumers make tradeoffs between privacy and personalization.

\section{De Bellis \& Johar (2020); Hoffman \& Novak (2017); Novak \& Hoffman (2019)}

Riegger et al. (2021); Timoshenko \& Hauser (2019)

Aiello et al. (2020); Inman \& Nikolova (2017); Martin and Murphy (2017); Okazaki et al. (2020); Plangger \& Montecchi (2020); Plangger and Watson (2015); Van Osselaer et al. (2020)
Tech giants such as Amazon, Google, Baidu, and others have launched or are rapidly developing AI platforms with increasingly skilled digital assistants. For example, Microsoft and Tencent have platforms for their own AI assistants (Cortana and Xiaowei), and virtual assistants such as Xiaoice, with over 40 million registered users, are "capable of uncannily human conversations" (Dawar, 2018).

Consumer digital signals can be detected with or without the consumer's knowledge and shared with the focal firm (e.g., Amazon in the case of Alexa) or beyond (e.g., other firms or even consumers able to access the data). According to recent research on a nationally representative sample of U.S. consumers conducted by PricewaterhouseCoopers, consumers worry that sensitive information they share with or in the presence of voice-enabled $\mathrm{AI}$ assistants may be stored and easily accessed by others, potentially making it unsafe (PricewaterhouseCoopers, 2018).

On the one hand, firms can mine consumer-generated data and data from other sources to identify major life changes - even before their customers could - and swiftly customize their marketing mix (e.g., Target's knowledge of a customer's pregnancy; Hill, 2012). On the other hand, recent updates to some mobile operating systems enhance privacy controls and give consumers greater control over who has access to their data (e.g., Apple).

Firms can obtain data from 21 different sensor technologies (e.g., microphones, temperature sensors, optical sensors). Billions of wearable electronic devices are sold each year, and a $\$ 5$ billion sensor market will drive a $\$ 160$ billion wearable technology market by 2028 (IDTechEx, 2017). Firms also capitalize on the macro aspect of customer journeys (e.g., IBM acquired the Weather Company; Facebook sources data from IHS Automotive, an industry intelligence firm used by car dealers and financial analysts; Dewey, 2016). 
Table 1 (continued)

\begin{tabular}{|c|c|c|c|}
\hline $\begin{array}{l}\text { Technology- } \\
\text { enabled } \\
\text { Customer } \\
\text { Journey Factors }\end{array}$ & Description & Illustrative Research & Examples from Current Marketing Practice \\
\hline $\begin{array}{l}\text { Customer } \\
\text { Journey and } \\
\text { Experience } \\
\text { Design }\end{array}$ & $\begin{array}{l}\text { Using advanced technologies and big data, } \\
\text { firms design seamless and frictionless } \\
\text { customer experiences across channels; } \\
\text { channel integration creates a stronger } \\
\text { customer experience. }\end{array}$ & $\begin{array}{l}\text { Fisher et al. (2019); Novak \& Hoffman } \\
\text { (2019); Shankar et al. (2011); Tan et al. } \\
\text { (2021); Yadav \& Pavlou (2014); } \\
\text { Villanova et al. (2021) }\end{array}$ & $\begin{array}{l}\text { Disney is strengthening its touchpoints } \\
\text { with its Magic Band individualized, } \\
\text { RFID-equipped wearable technology } \\
\text { that enables a seamless and frictionless } \\
\text { experience (Lemon \& Verhoef, 2016). }\end{array}$ \\
\hline $\begin{array}{l}\text { Customer } \\
\text { Journey } \\
\text { Mapping }\end{array}$ & $\begin{array}{l}\text { Customer input is not required for } \\
\text { technology-enabled customer journey } \\
\text { mapping, as customer data are available } \\
\text { from other sources and possible to } \\
\text { de-anonymize. }\end{array}$ & $\begin{array}{l}\text { De Haan et al. (2018); Grewal \& } \\
\text { Roggeveen (2020); Villanova et al. } \\
\text { (2021) }\end{array}$ & $\begin{array}{l}\text { MIT researchers were able to accurately } \\
\text { identify individuals in an anonymous } \\
\text { dataset by examining the date and } \\
\text { location of only four of their credit card } \\
\text { transactions (De Montjoye et al., 2015). }\end{array}$ \\
\hline $\begin{array}{l}\text { Regulator } \\
\text { Responsibility }\end{array}$ & $\begin{array}{l}\text { Regulators are rethinking the roles of } \\
\text { customers, firms, technology } \\
\text { developers, and governments to protect } \\
\text { customers' data and privacy and to } \\
\text { educate customers on their digital } \\
\text { signals and options. }\end{array}$ & $\begin{array}{l}\text { Banerjee (2019); Johnson et al. (2020); } \\
\text { Kamleitner \& Mitchell (2019); Tene \& } \\
\text { Polonetsky (2014); Todri (2021); } \\
\text { Walker et al. (2019) }\end{array}$ & $\begin{array}{l}\text { In 2014, the Marketing Research } \\
\text { Association expressed concern } \\
\text { regarding facial recognition technology } \\
\text { applications (Marketing Research } \\
\text { Association, 2014). In 2018, the case of } \\
\text { Cambridge Analytica, in which the } \\
\text { company collected psychographic data } \\
\text { using unauthorized and unethical } \\
\text { methods for political ad targeting, } \\
\text { resulted in investigations and may } \\
\text { trigger regulatory changes (Lapowsky, } \\
\text { 2019). }\end{array}$ \\
\hline
\end{tabular}

or from consumers who opt to preserve their privacy such as by using an anonymous browser. In such cases, while it is known that someone is visiting the website, the firm is unable to associate the visit with a specific individual. Privately observable signals are those that are only observable to the firm with whom the consumer is interacting. For such signals, the firm can often identify the individual by connecting identifiers such as an email address or phone number with a customer database. Publicly observable signals are those that are accessible to a broader audience, including other consumers and other firms. Though these publicly observable signals may reflect a particular stage of a journey with a specific firm, their visibility enables other firms to potentially act on them.

Related to signal visibility, another factor that affects the extent to which firms may leverage consumer digital signals is the extent to which consumer signals have been aggregated across consumers. At the most detailed level, signals are produced by an individual consumer, enabling firms to attribute behavior to a specific person. At the other extreme are signals that have been aggregated across consumers, limiting the extent to which they can be used to personalize the customer experience. The middle ground is where signals produced by consumers have been aggregated into segments. While not providing the clarity of signals emanating from individuals, segmented signals can still support personalization depending on the segmentation criteria. This is the basis for the recent proposal to replace third-party cookies for tracking individual web browsing activity with a set of technologies for tracking cohort-based web activities (Bohn, 2021).

\section{Consumer perspectives regarding the digital signals they emit}

\section{Awareness of signal emission}

One factor contributing to the extent to which consumers generate visible signals is their awareness of how these signals are used. Few consumers realize that firms are collecting digital traces of their behavior (Morey et al., 2015). While $97 \%$ of those surveyed expressed concern about how their data would be used by businesses and governments, fewer than $20 \%$ were aware that location data, online search activities, and connections on social networks are shared.

Information asymmetries further complicate this awareness problem (Acquisti et al., 2015). Prior to disclosing information to a firm, consumers know more about their willingness to pay for a product. As their emitted signals are gathered and analyzed by firms, though, they not only reveal their willingness to pay for one product but also their willingness to pay for other products. As firms gradually acquire more knowledge about consumers, technologies such as the automatic completion of text messages and recommendations for social media posts become more 
Table 2 Consumer signals throughout the journey

\begin{tabular}{|c|c|c|c|}
\hline Signal Visibility & purchase & Purchase & Post-purchase \\
\hline Publicly Observable & $\begin{array}{l}\text { Soliciting product recommendations } \\
\text { on a social media platform }\end{array}$ & $\begin{array}{l}\text { Sharing a product purchase on a social } \\
\text { media platform }\end{array}$ & $\begin{array}{l}\text { Posting product reviews on a social } \\
\text { media platform }\end{array}$ \\
\hline Privately Observable & $\begin{array}{l}\text { Reading product reviews on a } \\
\text { retailer's website }\end{array}$ & Purchasing from a retailer's website & $\begin{array}{l}\text { Calling customer service for assistance } \\
\text { or to return a product; soliciting } \\
\text { recommendations for a competing } \\
\text { product from a voice-activated device }\end{array}$ \\
\hline Anonymous & $\begin{array}{l}\text { Window shopping in front of a } \\
\text { retailer's store; anonymized } \\
\text { online browsing }\end{array}$ & Purchasing in a retailer's store with cash & $\begin{array}{l}\text { Sharing offline word of mouth about } \\
\text { the retailer }\end{array}$ \\
\hline
\end{tabular}

precise. This can lead to more value for consumers, whether through exposure to more relevant content or through reduced costs associated with completing tasks, making it harder for them to walk away. Consumers may therefore have trouble making informed decisions about privacy due to information asymmetries and switching costs.

Consumers may also vary in their awareness of data sharing arrangements. Taylor (2004) examines scenarios in which a firm can (or cannot) benefit from the sale of customer data to another firm for the purposes of price discrimination. He shows that when consumers do not anticipate the sale of their data, the firm stands to benefit at the expense of consumers. In contrast, when consumers anticipate the sale, the firm benefits from publicly announcing a policy of not selling its data due to the potential behavior of strategic consumers. Consumers' awareness of data sharing can thus affect the decisions they make.

Questions about consumers' awareness of data sharing policies have arisen in recent years. In 2013, the Federal Trade Commission reached a settlement with a flashlight app developer that failed to disclose to consumers it was collecting their device identifiers and location information (Kang, 2013). Although consumers were informed that such information was only being used for internal purposes and they could opt out of location data collection, the developer continued to share the data with third parties including advertising networks. Had consumers been aware of the data sharing arrangement, they may have opted to download an alternative app. Presenting consumers with a choice about data collection and data sharing policies not only grants them control over how their data are used, but also makes them more aware of the extent to which signals emitted through their routine activities are collected.

\section{Privacy concerns related to emitted signals}

While marketers' use of consumer data, such as demographics and purchase patterns, has been established, technological improvements have dramatically accelerated the pace at which such data are collected. Moreover, there is increased diversity in the data that can be collected, with the rate of collection of unstructured data such as text and video outpacing that of structured data (CIO, 2019). Activities which consumers may perceive as innocuous, such as online browsing and social media exchanges, are more readily available to marketers, offering insight into individuals while simultaneously fueling concerns over data privacy. Investigating the antecedents and consequences of privacy concerns, Phelps et al. (2001) found that a consumer's desire for control over personal information was a precursor to harboring privacy concerns. The authors also report that purchase behavior is lower among consumers with increased privacy concerns. The converse has also been found, as Tsai et al. (2011) show that consumers are more likely to purchase from online retailers believed to do a better job at protecting consumer privacy, and Tucker (2014) finds that privacy concerns decrease when consumers believe they have control over their privacy.

If consumers differ in their privacy preferences, are some willing to pay a premium for increased privacy? Tsai et al. (2011) find this to be the case: some consumers are willing to spend more at retailers that protect their privacy. Assessing the value consumers ascribe to privacy is not straightforward, though. How privacy is framed may affect valuations, leading to a contrast between the amount consumers would require to disclose private information (i.e., willingness to accept) and the amount they would spend to make public information private (i.e., willingness to pay) (Acquisti et al., 2015). Although prior studies have assessed the value that consumers ascribe to protecting personal data, the work of Acquisti et al. (2015) demonstrates that the value to consumers also depends on the status quo.

Consumer privacy preferences have evolved over time. Goldfarb and Tucker (2011) demonstrate that privacy concerns have increased, especially among older individuals. They suggest consumers have come to view more types of information as warranting privacy. That is, rather than being protective solely of sensitive information such as financial or health data, consumers are increasingly interested in safeguarding information that may be related to what would 
have once been considered benign, such as media consumption. The authors note these heightened privacy concerns affirm Nissenbaum's $(2010,2011)$ argument that privacy discourses need to keep pace with technological advancements. Today, consumers are accustomed to interacting with connected devices that not only provide answers to their questions and perform requested tasks but also record their queries and actions.

Some consumers wish to mitigate this "technology creep" (Schlogl, 2020). Consumers' awareness of data collection and sharing practices among firms may lead them to weigh the benefits of technology against the costs of sharing personal information. This tradeoff may motivate consumers to take more control of their digital privacy, a task which must be undertaken continually as newly developed technologies generate signals of which consumers were previously unaware. Consumers taking more control of their privacy would limit the extent to which firms can collect their digital signals. For example, privacy-friendly search engines enable consumers to reduce signal transmission during their purchase journey (Murphy, 2021).

Increasingly, consumers are being empowered to control access to their personal data. However, despite consumers' stated preferences, previous studies on privacy safeguards report that providing control over data collection has paradoxically little effect due to low awareness, confusion (Johnson et al., 2020), disclosure incentives (Kummer \& Schulte, 2019), transaction costs, and/or reassuring explanations (Athey et al., 2017). But, it is likely that consumers' deliberate choices in the context of mobile apps where privacy protections are now more salient may differ from previously investigated online contexts where the default settings grant data collection, suggesting that privacy preferences may differ by the device consumers use.

Indeed, customer reactions to firms acting on their digital signals may depend on their attitude toward privacy and obtrusiveness, which may differ across individuals (Goldfarb \& Tucker, 2011) and depend on the context (Acquisti et al., 2015). These reactions may also be affected by their motivations for disclosing information. For example, acquisition efforts may trigger backlash because consumers find personalized targeting more acceptable if their information was obtained via a previous interaction with a brand or revealed by them rather than inferred from an external entity (Kim et al., 2019). If consumers disclose such information to encourage competitive reactions, though, perhaps due to dissatisfaction with a current service provider, then competitor actions are likely to be received more positively (Ali et al., 2019).

\section{Privacy-personalization tradeoff}

Consumers differ in how they value the benefits of personalized marketing enabled by the collection and analysis of their signals. Blattberg and Deighton (1991) discuss the tradeoff between addressable marketing and privacy. Though consumers may report concerns with signal collection practices or the ways in which signals are acted on by firms, consumers may benefit from making signals available to firms. The ability to personalize marketing efforts based on the signals emitted by consumers can help reduce marketing inefficiencies and ultimately provide consumers with lower prices and improved products and services that meet their needs. As Blattberg and Deighton (1991, p. 12) recognize, "the tradeoff between marketing efficiency and privacy is a matter of continuous negotiation in a market economy." As technological advances enable the collection of consumer signals at an unprecedented scale, this sentiment appears to be just as true as it was 30 years ago.

The privacy calculus - the weighing of risks associated with sacrificing privacy against benefits such as personalized marketing - is ongoing (Dinev \& Hart, 2006; Plangger \& Montecchi, 2020). For example, when consumers' privacy concerns outweigh the expected benefits of personalization, firms' personalization efforts designed to increase switching costs may fall short (Chellappa \& Sin, 2005). Similarly, consumers who prefer increased firm transparency are often less willing to be digitally profiled (Awad \& Krishnan, 2006).

Most notably, in the context of location-based marketing, $\mathrm{Xu}$ et al. (2011) find that personal innovativeness and prior privacy experiences shape willingness to disclose information. These authors distinguish between covert personalization approaches that are based on signals collected through technological means (i.e., location-based services) and overt approaches initiated by users. Aguirre et al. (2015) similarly find that consumers react more favorably to personalized advertising that is supported by overtly collected consumer signals rather than those that are covertly gathered, indicating that trust building on the part of the firm is an essential element as consumers increasingly control who has access to their data. Additionally, Lambillotte et al. (2021) have recently shown that the negative impact of personalization on privacy concerns may be mediated by perceived control. Collectively, these insights are in line with Martin and Murphy's (2017) examination of the role of data privacy, in which they identify trust, personalization, and control as critical factors to consumer privacy.

Van Osselaer et al. (2020) take a step further in re-examining the privacy/personalization tradeoff by exploring the impact of providing personal information to employees. Beyond improving customer satisfaction and willingness to pay, as we may expect from the use of personal data, these authors discuss how the sharing of consumer and employee information can contribute to higher satisfaction among workers. Not only can consumers benefit from the resulting personalization, but firms can also benefit from collecting and using personal information to motivate employees to perform better. 
Societal factors may also affect consumers' privacy calculus, as the way in which organizations seek to collect and exploit consumer data may be made more salient to consumers based on the zeitgeist of the times. Zuboff (2019) documents shifts in the perceptions surrounding data collection and privacy in the wake of the September 11, 2001 terrorist attacks, identifying them as enabling today's practice of data collection and use. Several revelations pertaining to the way in which data have been gathered and used by businesses and governments - such as Edward Snowden's disclosures in 2013 (Greenwald et al., 2013), Cambridge Analytica's misuse of Facebook data (Confessore, 2018), the widespread misappropriation of photos from social media platforms for facial recognition (Hill, 2020), and the release of internal Facebook documents in 2021 (Allyn, 2021) - have also affected public perceptions relating to privacy. Such revelations of technology-based misuse may lead consumers to reevaluate their privacy calculus, becoming more wary of firms' intentions, particularly those firms with which they do not have strong relationships.

\section{Firm capabilities for using digital signals along the customer journey}

\section{Investing in technology for signal collection and use}

As firms seek to preempt the marketing actions of competitors, they often invest in technological innovation that enables the collection of consumer-level data that were previously undetectable and that are unavailable to competitors (Hagiu $\&$ Wright, 2020). For example, a firm may add location services to its mobile app. If consumers grant the necessary permissions, retailers can use these data to geo-conquest consumers when they are detected at a competitor's location (Fong et al., 2015). Alternatively, if a consumer is detected in the retailer's own store, the retailer may offer a promotion based on the consumer's location in the store in combination with the items she previously viewed in the app.

The augmentation of a previously analog process with digital sensors creates new opportunities for firms to improve their competitiveness (Hagiu \& Wright, 2020). Under the umbrella of digital transformation, firms have been steadily enhancing their signal-gathering competencies, as well as expanding capabilities to convert these signals into actionable marketing insights. Consider Uber and other ride-sharing applications: the overlaying of digital ride booking, car tracking, and pricing information enables better demand estimation, dynamic pricing models, and additional business opportunities. For instance, UberEats enables Uber to observe the restaurants from which consumers place orders, information that would have previously been unavailable because the transaction typically occurs outside of Uber's ecosystem. Seeking a competitive advantage, many firms are attempting to bypass their usual customers and business partners in favor of establishing a direct relationship with end-users, as illustrated by consumer packaged goods manufacturers exploring ways to reach individual consumers directly through digital channels (McKinsey \& Company, 2017).

One approach that can be deployed to capture signals and preclude other firms from doing so is the creation of "walled gardens" - entire ecosystems, controlled by the firm, in which consumer activity occurs. Voice-activated AI assistants (e.g., Google Home, Amazon Alexa) are prime examples. These AI devices provide a vast array of conveniences for consumers seeking to integrate information and services (Puntoni et al., 2021). By minimizing cost and risks and helping consumers navigate their choices (Gerhart, 2018), they also create an incentive for consumers to reside entirely within a given ecosystem, effectively cutting potential competitors off from consumers' signals (Agrawal et al., 2017). Some AI assistants are already ensuring that routine purchases "flow uninterrupted to households" (Dawar, 2018). Consider the subscription economy, where $15 \%$ of online shoppers have signed up for one or more subscriptions to receive products or services on a recurring basis. Such customers may find themselves in an automaticity loop, preventing them from considering other brands as they did before and from entering the traditional customer journey largely controlled by direct consumer-firm touchpoints.

When firms do not have the expertise to capture or leverage customer-level data, they may partner with technology providers (Oberoi et al., 2017). Mobile location data providers now offer firms access to mobile location data (Whittaker, 2019). A firm can both embed location services into its own app and acquire location data from third-party providers that aggregate location data collected from other apps. Consider the case of Nordstrom, who collaborated with two partners to collect consumer signals (primarily, the gender and the amount of time spent in a particular aisle) from their mobile devices while in store: Nomi, a retail analytics company whose technologies help retailers track individuals in stores and bring "the Amazon experience to the physical store" (Cook, 2013) and Euclid, a service that enables retailers to track individuals' movements through their smartphones' instore WiFi connections (Cohan, 2013).

These actions enable firms to increase the frequency with which a given mobile device is observed beyond what firms can capture on their own. Credit card transactions can also provide insight into consumer activity over time (De Montjoye et al., 2015). In contrast to a consumer's transactions with a firm, access to her credit card transactions enables firms to observe her activity across retailers and service providers. This enables firms to not only assess the size of wallet they receive from a consumer, but also the share of wallet they receive from that consumer in a given category (Du et al., 
2021). The sequence of transactions may also reveal the consumer's current location, the consumer's current mindset, and the consumer's shopping partners, which could further inform the firm's targeted promotion strategies.

In most of the aforementioned cases, the value of the data stems from the breadth of its coverage. Rather than building the solution in-house, firms often collaborate with technology providers who have established the necessary partnerships to capture a wide range of consumer digital signals and the necessary capabilities to interpret and package these signals in the actionable formats for the firms. While such collaborations enable firms to access the signals they are interested in, the same signals and insights could also be purchased by their competitors unless these partnerships are exclusive. The availability and adoption of such detailed data from third-party providers can pose a risk to firms, as the signals would be publicly visible.

Beyond the question of how firms collect signals, a fundamental question arises as to the perceived appropriateness of gathering different types of signals. Martin et al. (2020) note that data minimization is one means by which consumers' personal information can be protected, ensuring that only the necessary signals are collected. In addition to identifying the data necessary to support their marketing operations, firms should weigh how consumers will perceive the appropriateness of gathering these digital signals. While consumers place trust in firms when they choose to share their data, they do so with the belief that data will be used for purposes they deem appropriate. For example, whereas social media activities may inform creditworthiness (e.g., Wei et al., 2016), many consumers may not approve such use.

\section{Regulatory impact on signal collection and use}

Regulations such as the European Union's General Data Protection Regulation (GDPR) and the California Consumer Privacy Act (CCPA) intend to protect and empower consumers (Walker et al., 2019). Provisions such as the "Right to be forgotten" allow individual consumers to opt-out of online tracking, thereby limiting firms' abilities to follow them online. However, the impact of these regulations is curtailed by consumers' (often limited) awareness of their own rights (Tugend, 2015). When consumers are unaware of opting out of tracking or of requesting their profile be deleted, or when consumers decide that availing themselves of these rights is not worth the effort, regulation may not affect a firm's ability to collect digital signals.

Regulatory efforts nevertheless threaten to curb the use of some technologies. For instance, government agencies in San Francisco are prohibited from using facial recognition (Conger et al., 2019), and a bill has been proposed in the U.S. Senate to prevent the use of commercial facial recognition without first obtaining consent (Janofsky, 2019). A New
York City bill proposes banning the sale of mobile device location data by cell phone providers and app developers (Mays, 2019). Such proposals could limit the ability of firms to capture consumer-level data in the offline world. Moreover, new technologies continually raise new policy questions about privacy, leading lawmakers to continue considering potential legislation that prevents technological advancements from facilitating the identification of individual consumers.

Regulatory efforts may also curb the sharing of consumer data and make it difficult for competitors to track individuals at the consumer level, such as across websites or through the sharing of location data. For example, a regulation requiring that consumers opt into tracking is more likely to benefit the firm that already has a relationship with a consumer, since existing consumers are more likely to see the benefit of providing such data.

Regulations and norms governing the use of consumer data and the collection of consumer digital signals vary by country and industry. The healthcare and financial services industries are more heavily regulated than the retail and grocery industries, for instance, leading to likely differences between industries in the extent to which the collection and use of consumer digital signals can inform marketing efforts throughout the customer journey. However, as big tech firms start branching into other industries (health, grocery, restaurant), the extent to which regulations will be able to protect data previously siloed by industry remains to be seen.

\section{Tensions stemming from consumer preferences}

Consumer awareness of data collection practices is shaped by their interactions with multiple firms. This suggests that multiple firms with whom consumers interact are simultaneously affected by changes in consumer sensitivity to data collection and use. Firms may find themselves forced to react the missteps of other firms with whom consumers have negative experiences. Data breaches that occur at one IoT firm, for instance, may affect consumers' willingness to share data not only with other IoT firms, but also with retailers. Preventing and managing data breaches may therefore be key to avoiding consumer privacy protection strategies (Plangger \& Watson, 2015) such as intentionally disguising digital traces (e.g., going off the grid to avoid behavioral profiling; Electronic Privacy Information Center, 2020), as well as to avoiding feelings of creepiness (e.g., from targeted communications; Tene \& Polonetsky, 2014).

In light of consumer privacy concerns, Bleier et al. (2020) identify steps firms can take to mitigate those concerns and potentially derive a competitive advantage through privacy innovation. These steps include building trust, providing consumers control over the use of their data, and offering increased transparency in how digital signals are used. These authors also suggest the use of signals that are considered less 
sensitive. This is consistent with the perspective of only collecting the minimum data necessary to support decision making (e.g., Martin et al., 2020). Through such steps, rather than trying to minimize consumers' concerns about emitting signals that can be used by the firm, Bleier et al. (2020) contend that firms can encourage signal emission by providing sufficient value to outweigh the perceived costs that arise from sharing information. That is, requests for personal information can be viewed as opportunities to deliver increased value to the consumer, such as increasing perceived warmth (and the likelihood of providing the requested information) by requesting information during the post-purchase phase rather than the pre-purchase phase (Aiello et al., 2020).

\section{How the customer-firm relationship affects digital signal emission}

Firms that deliver desired content to consumers may succeed in encouraging consumers to reveal more information that can be tied to their individual behavior. For instance, consumers may agree to provide their email address in order to connect to a venue's WiFi when they perceive the benefit of free WiFi to outweigh the cost associated with sharing their email address. This privacy calculus may shift depending on several factors that characterize the individual's relationship with the firm. We discuss two salient aspects of the relationship between consumers and firms that may affect consumers' willingness to emit digital signals and ways in which they respond to firms' interpretation of and action on these signals.

\section{Signals and the customer relationship}

One factor that will affect the extent to which consumers engage with a firm is the consumer-firm relationship. Drawing on the customer equity framework (e.g., Blattberg \& Deighton, 1996; Kumar \& George, 2007; Rust et al., 2004), we consider three firm activities: acquiring new customers, developing existing customers, and retaining existing customers.

First, consider the challenges associated with acquiring prospective customers. For consumers with whom the firm does not have a relationship, the firm has no means of collecting signals via direct interactions. One option is to forego the use of detailed individual-specific information and use marketing tactics that rely on less granular data, whether at the segment or aggregate level. Another option is to acquire data about a particular prospect from business partnerships (i.e., second-party data) or third-party data providers (e.g., Neumann et al., 2019). While both tactics are available to the firm, they may not be equally effective for all consumers.

Consumers who prefer more privacy may view firm efforts to acquire information about them prior to starting a relationship as overly invasive. Though marketing to such consumers may be challenging due to their preference for privacy, any firm encountering these consumers will face the same "blind spots" created by these preferences. These consumers may be averse to personalized efforts, so such efforts may increase the risk of marketing inefficiency that is compounded by the limited insight the firm has on them (Bernritter et al., 2021). At the same time, the limited digital footprint left by these consumers makes them less attractive to competitors, resulting in a tradeoff between the costs to acquire such customers and the costs to maintain the relationship (e.g., Reinartz et al., 2005).

Next, consider consumers who emit digital signals detectable by any firm with the technological capabilities to collect them. Reliance on second- and third-party data enables marketing to be increasingly personalized (Oberoi et al., 2017). In addition, such data can be used to better sort prospects by their targeting worth via comparisons with current customers. While this can enable the firm to increase its communication efficiency, the firm should nevertheless be careful with such consumers. The advantage of observable signals during the acquisition stage may incur costs during the retention stage. Since other firms have access to public signals from these consumers, firms must constantly be aware that competitors may poach these consumers.

Once prospects have been acquired, individual preferences will still dictate how firms should engage with customers. Firms gather information about customer preferences through interactions, which may be informative of future behavior. For example, customers who regularly view content on Netflix may be less likely to churn, whereas an individual who has not logged onto the platform for a while may be at a higher risk. By collecting signals through customer interactions, firms may take steps to enhance and prolong the relationship, such as by proactively heading off churn. A key advantage of signals produced through these interactions is that they are generally available only to the firm, creating asymmetry in the information available to the firm and its competitors.

In contrast to digital signals that are available only to the firm with which a consumer interacts, consumers may also emit signals intended for the firm but visible to competitors. Sharing content on social media platforms, for example, can attract not only the attention of the firm, but also of its competitors. Ma et al. (2015) find that consumers may seek redress via social media. Service interventions can improve the relationship but may simultaneously prompt other consumers to seek redress as well, making such interventions tricky. Consequently, while publicly intervening to address customer complaints can help firms gain a reputation for excellent customer service, it can also prompt more customers to publicly air their grievances with the firm. Moreover, these signals are visible to competitors, enabling them to identify consumers 
who appear dissatisfied with their current service provider and are ripe for poaching. While customers who post regularly on social media can help the firm attract new customers through positive word of mouth, they may also be difficult to retain because the signals they produce make it easy for competitors to court them.

Firms that enjoy strong relationships with their customers can expect the signals emitted by these consumers to remain private. Even when signals are observable to a wider audience, loyalty may insulate the firm from conquesting efforts of its competitors. When consumers are open to exploring new products and services (e.g., when their contracts have expired), increasing and maintaining strong relationships with them may prevent them from shopping around.

\section{Signals and expectations}

Although consumers' signal emission enables firms to engage in more personalized marketing, this comes at a cost. Consumers producing signals through their interactions with the firm may expect more from the firms with whom they shared signals. For example, airline customers with loyalty status may expect to be recognized based on their phone number when they call an agent. To account for this expectation, firms can design chatbots by allowing for a conversation to continue across devices and conversation occasions. The increased expectations may suggest that more is demanded as part of the data and value exchange between customers and firms - not necessarily in a commercial exchange manner, but in the development of a more frictionless customer experience. Firms that fail to make the investments necessary to provide consumers with a frictionless experience risk losing them to firms that are willing to make them.

Firms must also recognize that heightened expectations are not restricted to their own industries. Consumers do not experience the world in neatly defined verticals. Rather, their perceptions, and consequently their expectations, may be shaped by their interactions with brands across categories (e.g., Yang et al., 2021). An Amazon customer who is accustomed to free two-day shipping may expect the same from a different business. Similarly, a consumer who is accustomed to the convenience of ride-sharing apps may expect an equal level of convenience in service settings such as banking and healthcare. This expectation spillover can gain competitive advantages which create barriers to entry when incumbents are capable of meeting and exceeding these expectations.

To summarize the challenges firms face in managing relationships with consumers, Table 3 illustrates the available signals and technology-enabled tactics firms may use with regard to consumers who vary in public signal generation.

\section{Signals and trust in the relationship}

Consumers' intentions to use personalized services are positively associated with their trust in the firm (Chellappa \& Sin, 2005). For these services to be produced and provided to the consumer, the consumer must be willing to share information with the firm. Consider a scenario in which a consumer has repeatedly sought to opt out of direct marketing efforts from the retailer but continues to receive marketing materials. If the consumer were prompted to share an email address with this retailer, the lack of trust may compel them to resist such efforts and refuse to willfully share information with this firm.

Investigating the relationship between privacy concerns and trust, Wu et al. (2012) conducted a cross-cultural survey,

Table 3 Challenges in managing consumer relationships

Technology-enabled Tactics for Firms
Acquiring Prospects
Retaining Customers

$\begin{array}{lll}\text { Consumer } & \text { Low } & \begin{array}{l}\text { Source of Signals: Anonymous or aggregated data } \\ \text { Tendency to }\end{array} \\ \text { Knowledge from Signals: Relatively generic } \\ \text { Emit Public } & & \text { Bottom Line: Elusive, but potentially high value } \\ \text { Signals } & & \end{array}$

High Source of Signals: Use of 2nd- and 3rd-party data Knowledge from Signals: Potentially detailed

Bottom Line: Ripe for acquiring due to the accessibility and specificity of their data, but competitors will also have opportunities. Such consumers may be of lower value to the firm because they may be poached by competitors
Source of Signals: (potentially limited) 1st party data

Knowledge from Signals: Any targeted activity and interaction must be conservative, as it should relate to the consumer's own observed activity

Bottom Line: Harder to poach because of data sharing concerns

Source of Signals: Incorporation of 2nd- and 3rd-party data with 1st-party data

Knowledge from Signals: Higher expectations because the firm has more signals they produced, and so should be capable of doing more

Bottom Line: Firms must invest in personalization capabilities or risk losing customers to firms that do. Likely the most at risk for being poached because they have fewer concerns generating public signals 
Table 4 Opportunities for future research

\begin{tabular}{ll}
\hline Research Path & Illustrative Research Questions \\
\hline Signal Generation by Consumers & - What factors affect consumers' willingness to share data? \\
& • Have perceptions of public vs. private information changed and if so, how? \\
& - To what extent do consumers understand data regulations and data sharing practices? \\
Firm Response to Signals & - To what extent do firms benefit from combining 1st-, 2nd-, and 3rd-party data? \\
& - What tactics can encourage consumers to share data? \\
Consumer Reactions & - Under what conditions are in-house development vs. technology partnerships preferable? \\
& - What factors affect consumers' acceptance of ongoing data capture?
\end{tabular}

finding that the content of privacy policies has a direct effect on online privacy concerns and trust. In particular, they found consumers are more trusting of websites that disclose what information is being collected and how the information is being used. In addition, providing consumers the ability to review, correct and remove personal information was found to positively relate to trust and negatively relate to privacy concerns. Moreover, consumers who reported higher levels of online privacy concerns were found to be less trusting. Both privacy concerns and trust shape a consumer's willingness to provide personal information.

As Chellappa and Sin (2005) and Wu et al. (2012) show, trust is a critical component of a firm's ability to collect detailed information from consumers. Among the levers firms may pull to affect consumer willingness to emit digital signals that firms can act on are the contents of the firm's privacy policy. Consumer-friendly provisions such as the ability to access and limit the use of data as well as how long the data are kept can foster trust. Additionally, being transparent in data collection and use is another means by which firms can increase consumers' willingness to provide signals. Grosso et al. (2020) examine different elements of trust to understand those factors that increase consumers' willingness to share information. The authors consider different types of data including identification, medical, financial, locational and lifestyle data. They find that trust in both the personnel and the retailer attenuate consumers' privacy concerns.

Just as firm decisions can enhance trust in the relationship, resulting in consumers being more likely to provide collectable signals, so can firm actions increase privacy concerns and quickly erode trust. Should this occur, consumers may elect to take actions to conceal their activities and identities, preventing firms from tracking them. ${ }^{2}$ For example, consumers can delete their registration records on e-commerce sites, scrub their social media and remove information from data

\footnotetext{
${ }^{2}$ Despite the fact that many consumers self-disclose more online than offline (Ho \& McLeod, 2008; Postmes et al., 1998), revealing information about their lifestyle, cultural identity, beliefs, and sentiment toward firms (Rakic \& Rakic, 2017), they overwhelmingly take steps to conceal their actions or identities while online (86\% of Americans; Pew Research Center, 2013).
}

aggregators. They can change deterministic identifiers such as email addresses, switch browsers, and clear cookies. Consumers can also use protected or untraceable browsers, advertisement blockers, VPNs, false or burner information, cash and gift cards, and P.O. boxes. With a combination of behavioral change and technology, they can become "ghosts" to marketers (Thomaz et al., 2020). Such behavior may stem from consumers' reactance to activities that appear to overtly target them (Clee \& Wicklund, 1980).

Consumer reactions may also depend on the credibility and relevance of firm actions. For example, excessive customer data collection may reduce the credibility of firm communications (Gardete \& Bart, 2018). However, if customers recognize economic benefits, for example, from a competitor that offers a product similar to the one marketed by the focal firm but for a lower price, they may react more favorably (Lin, 2019).

\section{Research agenda}

Marketing technology and the landscape in which marketers operate will continue to rapidly evolve. Tools will be developed that facilitate the collection and analysis of consumer signals. Consumers' future adoption of developing technologies will produce streams of signals that we have not yet considered. Rooted in the idea of consumer-generated signals, we propose an agenda for future research from the perspective of both consumers and firms. Returning to the framework illustrated in Fig. 1, we consider three research paths: (1) signal generation by consumers, (2) firms' response to consumer signals, and (3) consumer reactions to firm actions. We summarize the opportunities of each path in Table 4 .

\section{Research path 1: Signal generation by consumers}

Willingness to share The slightest actions by consumers generate signals that are often observable to firms. Given the state of marketing technology and the "always on" nature of data collection, fundamental questions arise about how this 
impacts consumers. One question concerns how consumers will react to firm requests for data. Depending on the nature of the request, consumer willingness to acquiesce may vary with the perceived sensitivity of the data, the industry, or the relationship consumers have with the firm. For instance, while consumers may not perceive risks from sharing information about the retailers from whom they shop, they may balk at requests to share information about their social connections. Ebbes and Netzer (2021), for example, combine activity on a professional social networking site with surveys soliciting information about a user's job-seeking status. While enabling the authors to observe "true" jobseeking status for some individuals which can then be related to the signals produced through their use of the social networking site, some users who are actually interested in finding a new employer may be reluctant to share such information. Understanding the conditions under which consumers are willing to share data warrants further research.

The decision to share data may hinge on the nature and value of the benefits marketers deliver in exchange. Understanding the types of appeals that increase consumers' willingness to opt-in to more prevalent signal collection will enable marketers to appropriately engage consumers. For example, if Amazon preemptively ships items to customers based on predictive models, will customers continue to engage in the same search processes that typically guide purchase decisions? While such business models may embed select retailers deeper into consumers' lives, the extent to which consumers are comfortable with the insight retailers have into their activities may be bounded. Context may also play a critical role in consumer decisions to share information. While critics raise concerns about the ability to precisely track individuals using mobile location data (Valentino-DeVries et al., 2018), calls are being made to use the same data to combat pandemics such as COVID-19. Ghose et al. (2019) investigate factors associated with consumer willingness to share location data to combat the pandemic. They find that devices in Democratic cities experience a larger increase in willingness to share location data (i.e., are less likely to opt out of sharing) than devices in Republican cities, and that those who socially distanced were more likely to share their location data. Identifying the conditions and use cases under which consumers are willing to emit additional signals would be beneficial to both marketers and policymakers.

(Re)defining public vs. private signals An important part of promoting signal emission is understanding how beliefs of what information consumers consider to be public versus private are shifting. The payment platform Venmo once publicly displayed transactions between two parties by default because "it's fun to share with friends in the social world" (Zhou, 2018). While Venmo has since updated its policies, users needed to restrict their posting to avoid public display. Perceptions about what information should remain private versus public can likely vary across consumers, making differences in privacy preferences an important area to explore.

Future research could also explore the rights consumers have to their data, as the question of who "owns" consumers" data gains importance. Content posted on social media platforms often becomes the property of social media platforms according to the terms of service. What about consumer profiles that have been produced through the aggregation of customer-generated digital signals? Future research could probe consumers' understanding of how different firms share data in order to inform regulations that aim to protect consumers from the potential misuse of their data. Regulations addressing data privacy will also need to specify the rights consumers have regarding the data pertaining to them, since their actions created the data.

Interconnected customer journeys Although prior research has often viewed the customer journey in discrete phases (pre-purchase, purchase, and post-purchase), our focus on the digital signals that consumers emit recognizes that the boundaries between phases of journeys, as well as between journeys themselves, are blurred. While marketers may classify the signals from different stages of the customer journey, signals may be emitted when customers are on one journey and captured by firms completely unrelated to that journey. Through the signals that consumers emit, explicit customer journeys are now interconnected. Firms can identify prospective customers by examining those types of journeys with respect to industries or brands that are precursors to consumers embarking on a new journey with their brand.

While signals serve as the links connecting explicit customer journeys, not all consumer activities are part of explicit journeys. Rather, consumers may continually emit digital signals through their everyday actions. This offers opportunities for firms to be proactive in their cultivation of customers by leveraging what may appear to be unrelated consumer signals.

\section{Research path 2: Firm response to signals}

Signal opacity A critical decision firms must make is whether and how to collect data about consumers for whom they have limited information. Firms may invest in developing technology to collect, interpret and act on signals emitted by consumers. Alternatively, or in addition, firms may acquire datasets that help them better understand consumers when merged with their own data. Research identifying data sources that allow firms to extend insights about customers regardless of the level to which signals have been aggregated across consumers and the visibility of the signals will be particularly useful. For example, social network and mobile location data may enable firms to generate insights about consumers who 
choose to provide limited data (e.g., Du et al., 2021). This technology development and/or partnership with technology providers will shed more light on the fraction of the customer journey that is currently not observed by the firm. Research into the characteristics of firms that are more likely to succeed in developing such technologies to support their marketing efforts compared with firms that who are better off collaborating with technology partners would be valuable.

Future research could also further investigate the trade-offs firms face when making decisions on capturing and acting on consumer signals. How much do firms gain from tracking the behavior of individual consumers throughout the journey? Could firms achieve similar results with less invasive approaches? If so, would consumers reward firms for adopting such tactics? The customer equity framework enables estimating the value associated with collecting different consumer signals at different journey stages, allowing firms to weigh the expected benefits of increased acquisition, expenditures and retention that can be attributed to the signals collected and acted on against the related costs. These costs include potential backlash from consumers for collecting and acting on such data. For firms that restrict the information they amass, assessing how this "data diet" impacts the effectiveness of their marketing activities and how different consumer segments may respond to more privacy-friendly marketing practices is important.

The dynamic nature of the trade-offs embedded in the managerial decisions regarding how to collect and act on consumer signals also deserves further investigation. Firm decisions on how to collect and act on consumer signals today may affect how consumers react, the signals they subsequently emit, and in turn, opportunities for the firm to benefit from tracking such signals in the future (e.g., Villanova et al., 2021). Consequently, firms prone to myopic marketing management (Mizik \& Jacobson, 2007) might be undertaking overly aggressive strategies when it comes to collecting and acting on digital consumer signals, especially when their management incentive compensation plans prioritize short-term revenues.

Promoting signal emission Firms can use an array of psychological levers to encourage technology adoption and subsequent signal emission. For example, leveraging prosocial motives may encourage consumers to share additional signals if they believe they are benefiting the greater good (Ghose et al., 2019; Hardy et al., 2018), such as to help public health efforts (Nicas \& Wakabayashi, 2020). Consumers may also be motivated to emit public signals to establish, communicate, or restore aspects of their identity (e.g., by posting appealing identity-relevant products on social media; Grewal et al., 2019; Reed et al., 2012). Firms may further increase the willingness to adopt technology and share data by capitalizing on consumers' motives to bolster their self-esteem. Consumers often share their product opinions with others to self-enhance, attract attention, or convey expertise (Babić Rosario et al., 2020; Berger, 2014). In turn, technologies that facilitate the dissemination of product assessments may increase consumer adoption of those technologies. Generally, while the lack of motives to adopt technologies can limit a firm's ability to detect signals from consumers, the lack of social motives may contribute to consumers actively guarding against signal emission. These considerations raise interesting questions about which type of psychological lever may most efficiently encourage consumers to produce signals and how firms may appropriately act upon this information.

Future research may also examine how the market settings and competition affect the profitability of such firm strategies as encouraging technology adoption as well as subsequent signal emission by consumers. Prior research has examined traffic stealing through competitive advertising on brand search, made possible by consumers emitting signals by using online search (Simonov \& Hill, 2021), and consequences of competitive mobile geotargeting, facilitated by consumers emitting location-based signals (Fong et al., 2015). Future contexts in which new technologies enable novel types of consumer signals emission will require further investigation.

Technology partnerships As noted previously, firms may choose to either develop technology solutions in-house or partner with a third-party company that has the necessary expertise, allowing the firm to bring the solution to market sooner. There are benefits to this route. In addition to the timeliness, using an available solution can ultimately result in lower costs. There are also costs and risks associated with working with technology partners to support signal collection and interpretation. For one, though working with third-party providers may enable firms to collect signals, it may also enable other firms access to signals. For example, location data providers may source information from hundreds of apps, using the signals gathered through such apps to support all of their clients. Future research can inform the conditions under which such collaborations offer the best path forward, and the conditions under which the firm may be better off building the necessary technologies on its own.

\section{Research path 3: Customer reactions}

Moving toward a surveillance state Consumer abilities to conduct activities away from governments or firm eyes are rapidly declining. Facial recognition and mobile location data make it difficult to remain anonymous offline while data aggregators make it difficult to remain anonymous online (Strobel, 2021). As regulations continue to develop in order to keep pace with technological advances and uses, another research question concerns the extent to which such technologies infringe on consumer privacy. Ultimately, better understanding how 
customers will react to firms' signal detection efforts and actions such as listening in on social media, personalized analytics, and data-driven marketing will inform a balanced approach between (1) firm efforts to "assemble the consumer brand" more consistently, efficiently, and accurately (Pridmore \& Lyon, 2011) to improve customer experiences and (2) increasing corporate transparency to address social and ethical implications of digital identification (Pridmore, 2013)

Establishing a new equilibrium Although individual firms may benefit from making investments in the collection of signals and acting upon these signals, future research is needed to understand how the marketplace may shift due to proactive data collection and targeting. One possibility is that increasingly detailed signals will render consumer targeting more precise (e.g., Villanova et al., 2021). This would enable firms to be more efficient with their marketing efforts. Additionally, if the marketing content is deemed relevant by consumers, the personalization efforts will not be interpreted as off-putting.

An alternative outcome is that the marketing content developed and disseminated by firms is not sufficiently distinct. This may arise due to overlaps in the audience being targeted or marketing content from multiple organizations becoming increasingly similar. Inundating consumers with marketing efforts may overwhelm them, ultimately reducing the efficacy of marketing. Moreover, if the high volume of marketing that consumers receive purports to be personalized, firms may face backlash from consumers who question just how much they benefit from making signals available to firms if they are marketed to in a perceived indiscriminate fashion. This may result in consumers being less willing to share detailed data, undermining firm investments in signal collection and analysis. Future research along this path should seek to identify not only the competitive equilibrium with regard to technological investments by multiple firms but also the conditions that may inform the types of industries that can expect favorable longterm outcomes.

\section{Conclusion}

In this article, we examine the role of technology throughout the customer journey by focusing on the notion of digital signals that consumers generate and the collection, interpretation, and action on these signals by firms. The goal of this article is not to replace the traditional customer journey framework, but rather to enhance it by highlighting insights enabled by technological advancements that facilitate marketing activities beyond the boundaries that consumers may have previously established.
The future role of technology in enabling firms to collect and interpret consumer signals throughout the customer journey cannot be understated. Firms that are successful in collecting and acting on consumer digital signals will gain a considerable and lasting advantage over competitors. We encourage researchers to build on the foundation we laid by investigating how firms can better leverage technology to develop relationships with consumers that create wins for firms and consumers alike. We hope our discussion of consumer signals and firm technological capabilities to collect them will spur further work on this topic.

\section{Declarations}

Conflict of interest The authors declare that they have no conflict of interest.

\section{References}

Acquisti, A., Brandimarte, L., \& Loewenstein, G. (2015). Privacy and human behavior in the age of information. Science, 347(6221), 509514.

Agrawal, A., J. Gans, \& A. Goldfarb (2017). How AI will change strategy: A thought experiment. Harvard Business Review.

Aguirre, E., Mahr, D., Grewal, D., De Ruyter, K., \& Wetzels, M. (2015). Unraveling the personalization paradox: The effect of information collection and trust-building strategies on online advertisement effectiveness. Journal of Retailing, 91(1), 34-49.

Aiello, G., Donvito, R., Acuti, D., Grazzini, L., Mazzoli, V., Vannucci, V., \& Viglia, G. (2020). Customers' willingness to disclose personal information throughout the customer purchase journey in retailing: The role of perceived warmth. Journal of Retailing, 96(4), 490-506.

Ali, S.N., Lewis, G., \& Vasserman, S. (2019). Voluntary disclosure and personalized pricing. NBER w26592.

Allyn, B. (2021, October 5). Here are 4 key points from the Facebook whistleblower's testimony on Capitol Hill. NPR. https://www.npr. org/2021/10/05/1043377310/facebook-whistleblower-franceshaugen-congress. Accessed January 4, 2022.

Anderl, E., Becker, I., von Wangenheim, F., \& Schumann, J. H. (2016). Mapping the customer journey: Lessons learned from graph-based online attribution modeling. International Journal of Research in Marketing, 33(3), 457-474.

Athey, S., Catalini, C., \& Tucker, C. E. (2017). The Digital Privacy Paradox: Small Money, Small Costs, Small Talk. No. w23488, National Bureau of Economic Research.

Awad, N. F., \& Krishnan, M. S. (2006). The personalization privacy paradox: An empirical evaluation of information transparency and the willingness to be profiled online for personalization. MIS Quarterly, 30(1), 13-28.

Babić Rosario, A., de Valck, K., \& Sotgiu, F. (2020). Conceptualizing the electronic word-of-mouth process: What we know and need to know about eWOM creation, exposure, and evaluation. Journal of the Academy of Marketing Science, 48, 422-448.

Banerjee, S. (2019). Geosurveillance, location privacy, and personalization. Journal of Public Policy \& Marketing, 38(4), 484-499.

Berger, J. (2014). Word of mouth and interpersonal communication: A review and directions for future research. Journal of Consumer Psychology, 24(4), 586-607. 
Bernritter, S. F., Ketelaar, P. E., \& Sotgiu, F. (2021). Behaviorally targeted location-based Mobile marketing. Journal of the Academy of Marketing Science, 49(4), 677-702.

Bettman, J. R., \& Park, C. W. (1980). Effects of prior knowledge and experience and phase of the choice process on consumer decision processes: A protocol analysis. Journal of Consumer Research, 7(3), 234-248.

Bharadwaj, N., Ballings, M., Naik, P. A., Moore, M., \& Arat, M. M. (2021). A new livestream retail analytics framework to assess the sales impact of emotional displays. Journal of Marketing, forthcoming, 86, 27-47.

Blattberg, R. C., \& Deighton, J. (1991). Interactive marketing: Exploiting the age of addressability. MIT Sloan Management Review, 33(1), 515.

Blattberg, R. C., \& Deighton, J. (1996). Manage marketing by the customer equity test. Harvard Business Review, 74(4), 136-144.

Bleier, A., Goldfarb, A., \& Tucker, C. E. (2020). Consumer privacy and the future of data-based innovation and marketing. International Journal of Research in Marketing, 37(3), 466-480.

Blut, M., \& Wang, C. (2020). Technology readiness: A Meta-analysis of conceptualizations of the construct and its impact on technology usage. Journal of the Academy of Marketing Science, 48(4), 649669.

Bohn, D. (2021) Privacy and Ads in Chrome Are About to Become Flocing Complicated. (March 30), Available at: https://www. theverge.com/2021/3/30/22358287/privacy-ads-google-chromefloc-cookies-cookiepocalypse-finger-printing. Accessed January 4, 2022.

Chellappa, R. K., \& Sin, R. G. (2005). Personalization versus privacy: An empirical examination of the online Consumer's dilemma. Information Technology and Management, 6(2), 181-202.

CIO. (2019, July 9). AI Unleashes the Power of Unstructured Data. CIO. https://www.cio.com/article/220347/ai-unleashes-the-power-ofunstructured-data.html. Accessed January 4, 2022.

Clee, M. A., \& Wicklund, R. A. (1980). Consumer behavior and psychological reactance. Journal of Consumer Research, 6(4), 389-405.

Cohan, P. (2013, May 9). How Nordstrom Uses WiFi To Spy on Shoppers. Forbes. https://www.forbes.com/sites/petercohan/2013/ 05/09/how-nordstrom-and-home-depot-use-wifi-to-spy-onshoppers/. Accessed January 4, 2022.

Confessore, N. (2018, April 4). Cambridge Analytica and Facebook: The Scandal and the Fallout So Far. The New York Times. https://www. nytimes.com/2018/04/04/us/politics/cambridge-analytica-scandalfallout.html. Accessed December 1, 2021.

Conger, K., Fausset, R., \& Kovaleski, S. F. (2019, May 14). San Francisco Bans Facial Recognition Technology. The New York Times. https://www.nytimes.com/2019/05/14/us/facial-recognitionban-san-francisco.html. Accessed May 1, 2021.

Cook, J. (2013, July 15). Nordstrom ends smartphone surveillance program that tracked in-store behavior of shoppers. GeekWire. https:// www.geekwire.com/2013/nordstrom-ends-smartphonesurveillance-program-tracked-instore-behavior-shoppers/. Accessed May 1, 2021.

Copeland, R. (2020, April 3). Google Offers User Location Data to Health Officials Tackling Coronavirus. Wall Street Journal. https:// www.wsj.com/articles/google-offers-user-location-data-to-healthofficials-tackling-coronavirus-11585893602. Accessed May 1, 2021.

Davenport, T., Guha, A., Grewal, D., \& Bressgott, T. (2020). How artificial intelligence will change the future of marketing. Journal of the Academy of Marketing Science, 48(1), 24-42.

Dawar, N. (2018). Marketing in the Age of Alexa. Harvard Business Review, (May-June).

De Bellis, E., \& Johar, G. V. (2020). Autonomous shopping systems: Identifying and overcoming barriers to consumer adoption. Journal of Retailing, 96(1), 74-87.
De Haan, E., Kannan, P. K., Verhoef, P. C., \& Wiesel, T. (2018). Device switching in online purchasing: Examining the strategic contingencies. Journal of Marketing, 82(5), 1-19.

De Keyser, A., Bart, Y., Gu, X., Liu, S. Q., Robinson, S. G., \& Kannan, P. K. (2021). Opportunities and challenges of using biometrics for business: Developing a research agenda. Journal of Business Research, 136, 52-62.

De Montjoye, Y.-A., Radaelli, L., \& Kumar Singh, V. (2015). Unique in the shopping mall: On the Reidentifiability of credit card metadata. Science, 347(6221), 536-539.

Dewey, C. (2016, August 19). 98 personal data points that Facebook uses to target ads to you. Washington Post. https://www.washingtonpost. com/news/the-intersect/wp/2016/08/19/98-personal-data-pointsthat-facebook-uses-to-target-ads-to-you/. Accessed November 4, 2019.

Dinev, T., \& Hart, P. (2006). An extended privacy Calculus model for ecommerce transactions. Information Systems Research, 17(1), 6180.

Du, R. Y., Netzer, O., Schweidel, D. A., \& Mitra, D. (2021). Capturing marketing information to fuel growth. Journal of Marketing, 85(1), 163-183.

Ebbes, P., \& Netzer, O. (2021). Using social network data to identify and target job seekers. Management Science. https://oi.org/10.1287/ mnsc. 2021.3995

Elberse, A. (2010). Bye-bye bundles: The unbundling of music in digital channels. Journal of Marketing, 74(3), 107-123.

Electronic Privacy Information Center (2020). Online Tracking and Behavioral Profiling. Available at: https://epic.org/privacy/ consumer/online-tracking/. Accessed December 22, 2020.

Fisher, M. L., Gallino, S., \& Xu, J. J. (2019). The value of rapid delivery in Omnichannel retailing. Journal of Marketing Research, 56(5), 732-748.

Fong, N. M., Fang, Z., \& Luo, X. (2015). Geo-conquesting: Competitive locational targeting of Mobile promotions. Journal of Marketing Research, 52(5), 726-735.

Forrester (2019). The US Digital Marketing Forecast, 2018 To 2023: Diverse Budget Priorities Will Boost Spend to Nearly $\$ 150$ Billion. (February 7), Available at: https://www.forrester.com/ report/The+US+Digital+Marketing+Forecast+2018+To+2023/-/ERES142558. Accessed December 22, 2020.

Gardete, P. M., \& Bart, Y. (2018). Tailored cheap talk: The effects of privacy policy on ad content and market outcomes. Marketing Science, 37(5), 733-752.

Gerhart, A. (2018, July 10). Alexa makes decision-making easier than ever-By making your choices for you. Quartz. https://qz.com/ 1323884/alexa-makes-decision-making-easier-than-ever-bymaking-your-choices-for-you/. Accessed November 4, 2019.

Ghose, A., Li, B., \& Liu, S. (2019). Mobile targeting using customer trajectory patterns. Management Science, 65(11), 5027-5049.

Goldfarb, A., \& Tucker, C. E. (2011). Online display advertising: Targeting and obtrusiveness. Marketing Science, 30(3), 389-404.

Greenwald, G., MacAskill, E., \& Poitras, L. (2013, June 11). Edward Snowden: The whistleblower behind the NSA surveillance revelations. The Guardian. https:/www.theguardian.com/world/2013/jun/ 09/edward-snowden-nsa-whistleblower-surveillance. Accessed November 4, 2019.

Grewal, D., \& Roggeveen, A. L. (2020). Understanding retail experiences and customer journey management. Journal of Retailing, 96(1), 38.

Grewal, L., \& Stephen, A. T. (2019). In Mobile we trust: The effects of Mobile versus nonmobile reviews on consumer purchase intentions. Journal of Marketing Research, 56(5), 791-808.

Grewal, L., Stephen, A. T., \& Coleman, N. V. (2019). When posting about products on social media backfires: The negative effects of consumer identity signaling on product interest. Journal of Marketing Research, 56(2), 197-210. 
Grewal, D., Gauri, D. K., Das, G., Agarwal, J., \& Spence, M. T. (2021). Retailing and Emergent Technologies. Journal of Business Research, 134(September, 198-202.

Grosso, M., Castaldo, S., Li, H. A., \& Larivière, B. (2020). What information do shoppers share? The effect of personnel-, retailer-, and country-trust on willingness to share information. Journal of Retailing, 96(4), 524-547.

Hagiu, A., \& Wright, J. (2020, January). When Data Creates Competitive Advantage. Harvard Business Review, Available at: https://hbr.org/ 2020/01/when-data-creates-competitive-advantage. Accessed July 29, 2021.

Hamilton, R., Ferraro, R., Haws, K. L., \& Mukhopadhyay, A. (2020). Traveling with companions: The social customer journey. Journal of Marketing, 85(1), 68-92.

Hardy, J., Veinot, T. C., Yan, X., Berrocal, V. J., Clarke, P., Goodspeed, R., Gomez-Lopez, I. N., Romero, D., \& Vydiswaran, V. G. V. (2018). User acceptance of location-tracking Technologies in Health Research: Implications for study design and data quality. Journal of Biomedical Informatics, 79, 7-19.

Hildebrand, C., \& Schlager, T. (2019). Focusing on others before you shop: Exposure to Facebook promotes conventional product configurations. Journal of the Academy of Marketing Science, 47(2), 291307.

Hill, K. (2012, February 16). How Target Figured Out A Teen Girl Was Pregnant Before Her Father Did. Forbes. https://www.forbes.com/ sites/kashmirhill/2012/02/16/how-target-figured-out-a-teen-girlwas-pregnant-before-her-father-did/. Accessed August 19, 2019.

Hill, K. (2020, January 18). The Secretive Company That Might End Privacy as We Know It. The New York Times. https://www. nytimes.com/2020/01/18/technology/clearview-privacy-facialrecognition.html. Accessed May 1, 2021.

Ho, S., \& McLeod, D. (2008). Social-psychological influences on opinion expression in face-to-face and computer-mediated communication. Communication Research, 35(2), 190-207.

Hoffman, D. L., \& Novak, T. P. (2017). Consumer and object experience in the internet of things: An assemblage theory approach. Journal of Consumer Research, 44(6), 1178-1204.

Howard, J. A., \& Sheth, J. N. (1969). The theory of buyer behavior. John Wiley \& Sons.

IDTechEx. (2017, July). Wearable sensors 2018-2028: Technologies, Markets \& Players. IDTechEx. https://www.idtechex.com/en/ research-report/wearable-sensors-2018-2028-technologies-marketsand-players/555. Accessed November 15, 2019.

Ingram, D. (2021, April 29). How to take advantage of Apple's new iPhone privacy features. NBC News. https://www.nbcnews.com/ tech/tech-news/apple-ios-145-update-know-new-privacy-featuresrena796. Accessed January 4, 2022.

Inman, J. J., \& Nikolova, H. (2017). Shopper-facing retail technology: A retailer adoption decision framework incorporating shopper attitudes and privacy concerns. Journal of Retailing, 93(1), 7-28.

Janofsky, A. (2019, October 30). Business Groups Push Back Against Proposed Facial-Recognition Bans. Wall Street Journal. https:// www.wsj.com/articles/business-groups-push-back-againstproposed-facial-recognition-bans-11572427801. Accessed May 1, 2021.

Johnson, G. A., Shriver, S. K., \& Du, S. (2020). Consumer privacy choice in online advertising: Who opts out and at what cost to industry? Marketing Science, 39(1), 33-51.

Kamleitner, B., \& Mitchell, V. (2019). Your data is my data: A framework for addressing interdependent privacy infringements. Journal of Public Policy \& Marketing, 38(4), 433-450.

Kang, C. (2013, December 5). Flashlight app kept users in the dark about sharing location data: FTC. Washington Post. https://www. washingtonpost.com/business/technology/flashlight-app-keptusers-in-the-dark-about-sharing-location-data-ftc/2013/12/05/ 1be26fa6-5dc7-11e3-be07-006c776266ed_story.html. Accessed October 28, 2019.

Kannan, P. K., \& Li, H. A. (2017). Digital marketing: A framework, review and research agenda. International Journal of Research in Marketing, 34(1), 22-45.

Kim, T., Barasz, K., \& John, L. K. (2019). Why am I seeing this ad? The effect of ad transparency on ad effectiveness. Journal of Consumer Research, 45(5), 906-932.

Kumar, V., \& George, M. (2007). Measuring and maximizing customer equity: A critical analysis. Journal of the Academy of Marketing Science, 35(2), 157-171.

Kummer, M., \& Schulte, P. (2019). When private information settles the bill: Money and privacy in Google's market for smartphone applications. Management Science, 65(8), 3470-3494.

Lambillotte, L., Bart, Y., \& Poncin, I. (2021). "When Does Information Transparency Reduce Downside of Personalization? Role of Need for Cognition and Perceived Control," working paper.

Lapowsky, I. (2019, March 17). How Cambridge Analytica Sparked the Great Privacy Awakening. . https://www.wired.com/story/ cambridge-analytica-facebook-privacy-awakening/. Accessed October 28, 2019.

Laziuk, E. (2021, May 25). iOS 14 opt-in rate - weekly updates since launch. Flurry. https://www.flurry.com/blog/ios-14-5-opt-in-rateidfa-app-tracking-transparency-weekly/. Accessed January 4, 2022.

Lemon, K. N., \& Verhoef, P. C. (2016). Understanding customer experience throughout the customer journey. Journal of Marketing, 80(6), 69-96.

Leung, E., Paolacci, G., \& Puntoni, S. (2018). Man versus machine: Resisting automation in identity-based consumer behavior. Journal of Marketing Research, 55(6), 818-831.

Libai, B., Bart, Y., Gensler, S., Hofacker, C. F., Kaplan, A., Kötterheinrich, K., \& Kroll, E. B. (2020). Brave New World? On AI and the Management of Customer Relationships. Journal of Interactive Marketing, 51, 44-56.

Lin, T. (2019). "Valuing Intrinsic and Instrumental Preferences for Privacy," working paper, Available at https://ssrn.com/abstract= 3406412. Accessed December 22, 2020.

Longoni, C., Bonezzi, A., \& Morewedge, C. (2019). Resistance to Medical Artificial Intelligence. Journal of Consumer Research, 46(4), 629-650.

Ma, L., Sun, B., \& Kekre, S. (2015). The Squeaky Wheel Gets the Grease-An Empirical Analysis of Customer Voice and Firm Intervention on Twitter. Marketing Science, 34(5), 627-645.

Marketing Research Association. (2014, February 6). mra facial-recognition-mr-applications_2-6-14.pdf. Insights Association. https:// www.insightsassociation.org/sites/default/files/misc_files/mra facial-recognition-mr-applications 2-6-14.pdf. Accessed October $1,2020$.

Martin, K. D., \& Murphy, P. E. (2017). The role of data privacy in marketing. Journal of the Academy of Marketing Science, 45(2), $135-155$.

Martin, K. D., Kim, J. J., Palmatier, R. W., Steinhoff, L., Stewart, D. W., Walker, B. A., Wang, Y., \& Weaven, S. K. (2020). Data privacy in retail. Journal of Retailing, 96(4), 474-489.

Mays, J. C. (2019, July 23). New York City to Consider Banning Sale of Cellphone Location Data. The New York Times. https://www. nytimes.com/2019/07/23/nyregion/cellphone-tracking-locationdata.html. Accessed January 4, 2022.

McKinsey \& Company. (2017, November 8). Should CPG manufacturers go direct to consumer-and, if so, how? McKinsey \& Company. https://www.mckinsey.com/industries/consumer-packaged-goods/ our-insights/should-cpg-manufacturers-go-direct-to-consumer-andif-so-how. Accessed October 1, 2020.

Melumad, S., Inman, J. J., \& Pham, M. T. (2019). Selectively emotional: How smartphone use changes user-generated content. Journal of Marketing Research, 56(2), 259-275. 
Mizik, N., \& Jacobson, R. (2007). Myopic marketing management: Evidence of the phenomenon and its long-term performance consequences in the SEO context. Marketing Science, 26(3), 361-379.

Morey, T., Forbath, T., \& Schoop, A. (2015, May), Customer Data: Designing for Transparency and Trust. Harvard Business Review, Available at: https://hbr.org/2015/05/customer-data-designing-fortransparency-and-trust. Accessed July 27, 2021.

Murphy, H. (2021). Can pro-privacy search engines replace Google?. Search Engine Journal, November, Available at https://www. searchenginejournal.com/pro-privacy-searchengines/424201. Accessed January 9, 2022.

Neumann, N., Tucker, C. E., \& Whitfield, T. (2019). Frontiers: How effective is third-party consumer profiling? Evidence from field studies. Marketing Science, 38(6), 918-926.

Nguyen, G. (2021). Google Announces its Own Version of App Tracking Transparency. Search Engine Land (June 4), https:// searchengineland.com/google-announces-its-own-version-of-apptracking-transparency-349272.

Nicas, J., \& Wakabayashi, D. (2020, April 10). Apple and Google team up to 'contact trace' the coronavirus. The New York Times. https:// www.nytimes.com/2020/04/10/technology/apple-googlecoronavirus-contact-tracing.html. Accessed January 4, 2022.

Nissenbaum, H. (2010). Privacy in context: Technology, policy, and the integrity of social life. Stanford University Press.

Nissenbaum, H. (2011, November). At What Cost?: The Privacy Issues that Must Be Considered in a Digital World. The Futures of Entertainment Conference, MIT Program in Comparative Media Studies.

Novak, T. P., \& Hoffman, D. L. (2019). Relationship journeys in the internet of things: A new framework for understanding interactions between consumers and smart objects. Journal of the Academy of Marketing Science, 47(2), 216-237.

Oberoi, P., Patel, C., \& Haon, C. (2017). Technology sourcing for website personalization and social media marketing: A study of Eretailing industry. Journal of Business Research, 80(November, 1023.

Okazaki, S., Eisend, M., Plangger, K., de Ruyter, K., \& Grewal, D. (2020). Understanding the Strategic Consequences of Customer Privacy Concerns: A Meta-Analytic Review. Journal of Retailing, 96(4), 458-73.

Oracle (2018, October 22). Oracle Helps Brands Eliminate Customer Blind Spots. Available at: https://www.oracle.com/emea/corporate/ pressrelease/oow18-oracle-cx-unity-2018-10-22.html. Accessed December 22, 2020.

Pew Research Center (2013, September 5). Anonymity, privacy, and security online. Pew Research Center: Internet, Science \& Tech. Available at: https://www.pewresearch.org/internet/2013/09/05/ anonymity-privacy-and-security-online.

Phelps, J. E., D'Souza, G., \& Nowak, G. J. (2001). Antecedents and consequences of consumer privacy concerns: An empirical investigation. Journal of Interactive Marketing, 15(4), 2-17.

Plangger, K., \& Montecchi, M. (2020). Thinking beyond privacy Calculus: Investigating reactions to customer surveillance. Journal of Interactive Marketing, 50, 32-44.

Plangger, K., \& Watson, R. T. (2015). Balancing customer privacy, secrets, and surveillance: Insights and management. Business Horizons, 58(6), 625-633.

Postmes, T., Spears, R., \& Lea, M. (1998). Breaching or building social boundaries? SIDE-effects of computer-mediated communication. Communication Research, 25, 689-715.

PricewaterhouseCoopers. (2018). Consumer intelligence series: Prepare for the voice revolution. $P w C$. https://www.pwc.com/us/en/services/ consulting/library/consumer-intelligence-series/voice-assistants. $\mathrm{html}$. Accessed November 15, 2019.

Pridmore, J. (2013). Collaborative surveillance: configuring contemporary marketing practice. In K. Ball \& L. Snider (Eds.), In The
Surveillance-Industrial Complex: A Political Economy of Surveillance (1st ed., pp. 121-135). New York, NY: Routledge..

Pridmore, J., \& Lyon, D. (2011). Marketing as surveillance: Assembling consumers as brands. Inside marketing: Practices, ideologies, devices, 115-36.

Puntoni, S., Walker Reczek, R., Giesler, M., \& Botti, S. (2021). Consumers and artificial intelligence: An experiential perspective. Journal of Marketing, 85(1), 131-151.

Rakic, B., \& Rakic, M. (2017). Facebook or the book of faces as a database for customer profiles, marketing communications and applications. Economic and Social Development: Book of Proceedings, 48-58.

Ransbotham, S., Lurie, N. H., \& Liu, H. (2019). Creation and consumption of Mobile word of mouth: How are Mobile reviews different? Marketing Science, 38(5), 773-792.

Reed, A., Forehand, M. R., Puntoni, S., \& Warlop, L. (2012). Identitybased consumer behavior. International Journal of Research in Marketing, 29(4), 310-321.

Reinartz, W., Thomas, J. S., \& Kumar, V. (2005). Balancing acquisition and retention resources to maximize customer profitability. Journal of Marketing, 69(1), 63-79.

Riegger, A. S., Klein, J. F., Merfeld, K., \& Henkel, S. (2021). Technology-enabled personalization in retail stores: Understanding drivers and barriers. Journal of Business Research, 123, 140-155.

Rust, R. T., Lemon, K. N., \& Zeithaml, V. A. (2004). Return on marketing: Using customer equity to focus marketing strategy. Journal of Marketing, 68(1), 109-127.

Schamp, C., Heitmann, M., \& Katzenstein, R. (2019). Consideration of ethical attributes along the consumer decision-making journey. Journal of the Academy of Marketing Science, 47(2), 328-348.

Schlogl, L. (2020). Leapfrogging into the Unknown: The Future of Structural Change in the Developing World, Vienna, Austria: United Nations University World Institute for Development Economics Research, Available at: https://doi.org/10.35188/UNUWIDER/2020/782-8.

Shankar, V., Inman, J. J., Mantrala, M., Kelley, E., \& Rizley, R. (2011). Innovations in shopper marketing: Current insights and future research issues. Journal of Retailing, 87, S29-S42.

Shankar, V., Kalyanam, K., Setia, P., Golmohammadi, A., Tirunillai, S., Douglass, T., Hennessey, J., Bull, J., \& Waddoups, R. (2021). How technology is changing retail. Journal of Retailing, 97(1), 13-27.

Simonov, A., \& Hill, S. (2021). Competitive advertising on brand search: Traffic stealing and click quality. Marketing Science, 40(5), 923945.

Srinivasan, S., Rutz, O. J., \& Pauwels, K. (2016). Paths to and off purchase: Quantifying the impact of traditional marketing and online consumer activity. Journal of the Academy of Marketing Science, 44(4), 440-453.

Stanley, A. (2021, October 31). Apple's privacy policy cost snap, Facebook, twitter, and YouTube an estimated $\$ 9.85$ billion in revenue. Gizmodo. https:/gizmodo.com/apples-privacy-policy-costsnap-facebook-twitter-and-1847971994. Accessed January 4, 2022.

Statista. (2022). Number of internet of things (IoT) connected devices worldwide in 2018, 2023, and 2030 (in billions). Statista. https:// www.statista.com/statistics/802690/worldwide-connected-devicesby-access-technology/. Accessed January 4, 2022.

Strobel, W. P. (2021). Biometrics, Smartphones, Surveillance Cameras Pose New Obstacles for U.S. Spies. Wall Street Journal (November 27), https://www.wsj.com/articles/biometrics-smartphonessurveillance-cameras-pose-new-obstacles-for-u-s-spies11638009002. Accessed January 4, 2022.

Suk, M., \& Prabhakaran, B. (2014). Real-time Mobile Facial Expression Recognition System - A Case Study. Columbus, OH: IEEE, 13237. 
Tan, Y.-C., Chandukala, S. R., \& Reddy, S. K. (2021). Augmented Reality in Retail and Its Impact on Sales. Journal of Marketing, forthcoming, 86, 48-66.

Taylor, C. R. (2004). Consumer privacy and the market for customer information. RAND Journal of Economics, 35(4), 631-650.

Tene, O., \& Polonetsky, J. (2014). A theory of creepy: Technology, privacy, and shifting social norms. Yale Journal of Law and Technology, 16(1), 59-102.

Thomaz, F., Salge, C., Karahanna, E., \& Hulland, J. (2020). Learning from the dark web: Leveraging conversational agents in the era of hyper-privacy to enhance marketing. Journal of the Academy of Marketing Science, 48(1), 43-63.

Timoshenko, A., \& Hauser, J. R. (2019). Identifying customer needs from user-generated content. Marketing Science, 38(1), 1-20.

Todri, V. (2021). Frontiers: The Impact of Ad-Blockers on Online Consumer Behavior. Marketing Science, forthcoming.

Tong, S., Luo, X., \& Xu, B. (2020). Personalized Mobile marketing strategies. Journal of the Academy of Marketing Science, 48(1), 64-78.

Tsai, J. Y., Egelman, S., Cranor, L., \& Acquisti, A. (2011). The effect of online privacy information on purchasing behavior: An experimental study. Information Systems Research, 22(2), 254-268.

Tucker, C. E. (2014). Social networks, personalized advertising, and privacy controls. Journal of Marketing Research, 51(5), 546-562.

Tugend, A. (2015). "Key to Opting Out of Personalized Ads, Hidden in Plain View," New York Times (December 21), https://www.nytimes. com/2015/12/21/business/media/key-to-opting-out-ofpersonalized-ads-hidden-in-plain-view.html. Accessed July 15, 2019.

Temkin, D. (2021, March 3). Charting a course towards a more privacyfirst web. Google. https://blog.google/products/ads-commerce/amore-privacy-first-web/. Accessed 21 January 2022.

Valentino-DeVries, J., Singer, N., Keller, M. H., \& Krolik, A. (2018, December 10). Your apps know where you were last night, and They're not keeping it secret. The New York Times. https://www. nytimes.com/interactive/2018/12/10/business/location-dataprivacy-apps.html. Accessed January 4, 2022.

Van Osselaer, S. M., Fuchs, C., Schreier, M., \& Puntoni, S. (2020). The power of personal. Journal of Retailing, 96(1), 88-100.

Verhoef, P. C., Lemon, K. N., Parasuraman, A., Roggeveen, A., Tsiros, M., \& Schlesinger, L. A. (2009). Customer experience creation: Determinants, dynamics and management strategies. Journal of Retailing, 85(1), 31-41.

Villanova, D., Bodapati, A., Puccinelli, N., Tsiros, M., Goodstein, R., Kushwaha, T., Suri, R., Ho, H., Brandon, R., \& Hatfield, C.
(2021). Retailer Marketing Communications in the Digital age: Getting the right message to the right shopper at the right time. Journal of Retailing, 97(1), 116-132.

Walker, K. L., Milne, G. R., \& Weinberg, B. D. (2019). Optimizing the future of innovative technologies and infinite data. Journal of Public Policy \& Marketing, 38(4), 403-413.

Ward, A. F., Duke, K., Gneezy, A., \& Bos, M. W. (2017). Brain drain: The mere presence of One's own smartphone reduces available cognitive capacity. Journal of the Association for Consumer Research, 2(2), 140-154.

Wei, Y., Yildirim, P., van den Bulte, C., \& Dellarocas, C. (2016). Credit scoring with social network data. Marketing Science, 35(2), 234 258.

Whittaker, Z. (2019, January 9). Despite promises to stop, US cell carriers are still selling your real-time phone location data. TechCrunch. https://techcrunch.com/2019/01/09/us-cell-carriers-still-sellingyour-location-data/. Accessed January 4, 2022.

Wu, J., \& Lederer, A. (2009). A Meta-analysis of the role of environmentbased voluntariness in information technology acceptance. MIS Quarterly, 33(2), 419-432.

Wu, K.-W., Huang, S. Y., Yen, D. C., \& Popova, I. (2012). The effect of online privacy policy on consumer privacy concern and trust. Computers in Human Behavior, 28(3), 889-897.

Xu, H., Luo, X. R., Carroll, J. M., \& Rosson, M. B. (2011). The personalization privacy paradox: An exploratory study of decision making process for location-aware marketing. Decision Support Systems, 51(1), 42-52.

Yadav, M. S., \& Pavlou, P. A. (2014). Marketing in Computer-Mediated Environments: Research synthesis and new directions. Journal of Marketing, 78(1), 20-40.

Yang, Y., Zhang, K., \& Kannan, P. K. (2021). "EXPRESS: Identifying market structure: A deep network representation learning of social engagement," Journal of Marketing, Available at: https://doi.org/10. $1177 / 00222429211033585$.

Zhou, M. (2018, July 20). Venmo transactions are public by default as part of its social strategy. CNET. https://www.cnet.com/tech/ services-and-software/venmo-explains-why-transactions-arepublic-by-default/. Accessed January 4, 2022.

Zuboff, S. (2019). The age of surveillance capitalism: The fight for a human future at the new frontier of power. Profile Books.

Publisher's note Springer Nature remains neutral with regard to jurisdictional claims in published maps and institutional affiliations. 